Research Article

\title{
Evaluation of mass drug administration for elimination of lymphatic filariasis in Goa, India
}

\author{
S.G. Perni ${ }^{1}$, D.D. Motghare ${ }^{1}$, A.M. Ferreira ${ }^{1}$, S.S. Perni ${ }^{2}$, F.S. Vaz ${ }^{1 *}$, M.S. Kulkarni ${ }^{1}$, \\ S. Govekar ${ }^{2}$
}

${ }^{1}$ Department of Preventive and Social Medicine, Goa Medical College, Bambolim, Goa
${ }^{2}$ National Vector Borne Disease Control programme, Directorate of Health Services, Government of Goa, Panaji, Goa

Received: 07 May 2015

Accepted: 07 June 2015

\section{*Correspondence:}

Dr. Frederick S. Vaz,

E-mail: frederickvaz@rediffmail.com

Copyright: (C) the author(s), publisher and licensee Medip Academy. This is an open-access article distributed under the terms of the Creative Commons Attribution Non-Commercial License, which permits unrestricted non-commercial use, distribution, and reproduction in any medium, provided the original work is properly cited.

\section{ABSTRACT}

Background: The most practical and feasible method of controlling lymphatic filariasis is the rapid reduction of microfilarial load in the community by annual mass drug administration (MDA) of a single dose of diethyl Carbamazine Citrate. The objective of the study aimed at the trends in coverage and compliance of Mass Drug Administration with Diethyl Carbamazine Citrate (DEC) for elimination of lymphatic filariasis in Goa.

Methods: Cross-sectional population surveys were conducted after every yearly round of MDA with DEC for the years 2006, 2007, 2008 and 2010 as part of independent assessment of MDA. Four clusters were selected from each district, each cluster having 30 households. A pretested questionnaire was used to interview the study participants and the responses were recorded in pre-designed formats. The data was analysed using SPSS package. Coverage rate, compliance rate, coverage-compliance gap and effective coverage rate were calculated.

Results: The total coverage ranged from a high of $95.55 \%$ in the year 2007 and a low of $84.94 \%$ in 2006 . The total compliance rate fluctuated between a low of $64.68 \%$ in 2010 and a high of $93.47 \%$ in 2006 . Total coveragecompliance gap ranged from a high of $35.31 \%$ in the year 2010 and a low of $6.52 \%$. Overall coverage and compliance rates were consistently higher in rural areas compared to urban areas for all the years under study.

Conclusion: Coverage, compliance, coverage-compliance gap and effective coverage rate were found to be consistently lower in urban areas compared to rural areas. For the state to reach elimination targets, the MDA strategy implementation would require thorough review and revamping. Action on this front would ensure that gains made in filarial elimination are sustained eventually leading to elimination of lymphatic filariasis in the state of Goa.

Keywords: Mass Drug Administration, Filaria, Diethyl carbamazine citrate, Coverage, Compliance

\section{INTRODUCTION}

Lymphatic filariasis (LF) is one of the major public health problems in India causing social stigmatization, disabilities and immense economic loss. The International Task Force for Disease Eradication had identified Lymphatic filariasis as an eradicable or potentially eradicable disease. ${ }^{1}$ The most practical and feasible method of controlling lymphatic filariasis is the rapid reduction of microfilarial load in the community by annual mass drug administration (MDA) of a single dose of diethyl Carbamazine Citrate (DEC). ${ }^{2}$ It has been shown that 5-10 rounds of treatment with $75-80 \%$ coverage could possibly eradicate LF by reducing transmission to low levels. ${ }^{3}$ Lymphatic filariais has already been eliminated in countries like Japan, South Korea, and Taiwan through the MDA strategy. ${ }^{4}$ Annual MDA with DEC was implemented as a pilot project in India in 1996-97 and has since been extended to cover all endemic districts in the country. ${ }^{5}$ National filaria Day is being observed since 2004 in endemic districts in order to achieve elimination of lymphatic Filariasis by the Year 2015. 
Goa is a small state with a population of around 1.4 million on the west coast of India and is administered as two districts. Both the districts of Goa have been classified as endemic areas for lymphatic filariasis. The very first round of MDA with single dose of DEC was conducted in 2004 on pilot basis in selected areas. Subsequent rounds have been held every year covering the entire state. The programme was run through the network of primary health centres (PHCs), Urban health centres (UHCs) and community health centres (CHCs) under the supervision of programme officials of the National Vector Borne Disease Control Programme at the state headquarters. DEC tablets were distributed based on age by peripheral health workers who were called drug distributors (DD). Pregnant women, children under two years and seriously ill individuals were not given the drug as per the programme guidelines.

\section{METHODS}

Cross-sectional population surveys were conducted after every yearly round of MDA with DEC for the years 2006, 2007, 2008 and 2010 as part of independent assessment of MDA. The assessment was conducted by independent a team not directly connected with the MDA programme and completed within two to three weeks of MDA to prevent recall bias. The assessment was done by a team of doctors from the medical college.

The assessment was carried out in both the districts of the state (North and South Goa) which are classified as endemic for filariasis. Four clusters were selected from each district, each cluster having 30 households. Three clusters were from rural areas and one from urban area. For selection of clusters following procedure was followed: for rural clusters, primary health centre (PHC) areas were divided into low, medium and high on basis of drug distribution coverage. From each category one PHC area was selected at random. From each PHC area one village was randomly selected. For urban areas one ward was selected from a medium coverage town randomly. A cluster of thirty households was sampled in each of the selected village or ward.

A pretested questionnaire was used to interview the study participants and the responses were recorded in predesigned formats. The data was analysed using SPSS package. Eligible rate, Coverage rate, compliance rate, coverage-compliance gap and effective coverage rate were calculated. Individuals more than two years of age except pregnant women and seriously ill were eligible to receive Diethyl Carbamazine Citrate (DEC) under MDA. The 'coverage' of MDA was defined as proportion of eligible persons who were distributed drug DEC by the Drug Distributor. The 'Compliance rate' of MDA was defined as proportion of population covered under MDA who actually consumed drug DEC. 'CoverageCompliance gap' was defined as the difference between coverage and compliance expressed as a percentage of population covered under MDA. 'Effective coverage' was defined as number of people who actually consumed the DEC tablets out of all persons eligible to receive DEC tablets.

\section{RESULTS}

Post MDA evaluation was done for the years 2006, 2007, 2008 and 2010. The population studied ranged from 1131 in the year 2008 to 1405 in the year 2007. The proportion of urban population studied varied from $22.23 \%$ in 2006 to $25.19 \%$ in 2007 . There is a variation in the population studied by year as household was the sampling unit. Overall around $96.08 \%$ to $98.52 \%$ of the study population was found to be eligible to receive DEC tablets under the MDA strategy across various years.

As far as coverage of MDA was concerned it was consistently high in rural areas (i.e. more than 90\%) for all the years, whereas in urban areas it fluctuated from a low of merely $43.38 \%$ in 2010 to high of $89.65 \%$ in the year 2007 (Table 1). The total coverage ranged from a high of $95.55 \%$ in the year 2007 and a low of $84.94 \%$ in 2006.

Compliance rate was high in the rural population across all the years. The highest compliance in rural was observed at $96.19 \%$ in 2008 and the lowest of $65.49 \%$ was observed in the year 2010. The compliance in urban areas was lower than rural areas for all the years under study the lowest compliance was $58.59 \%$ in 2010 and the highest compliance was $85.57 \%$ in 2007 (Table 1). The total compliance rate fluctuated between a low of $64.68 \%$ in 2010 and a high of $93.47 \%$ in 2006.

Coverage-compliance gap was consistently higher in urban areas compared to rural areas across all the years. As far as urban areas were concerned the coveragecompliance gap ranged from $14.42 \%$ to $41.4 \%$ whereas for rural areas it ranged from $3.8 \%$ to $34.50 \%$. Total coverage-compliance gap ranged from a high of $35.31 \%$ in the year 2010 and a low of $6.52 \%$ in the year 2006 .

The effective coverage rate which can be considered as a measure of the actual success of the MDA strategy since it factors in both coverage and compliance was calculated. Overall effective coverage ranged from a high of $87.25 \%$ in 2007 to a low of $54.51 \%$ in 2010 . Effective coverage was substantially higher in rural areas compared to urban areas. In urban areas effective coverage ranged from low of $25.42 \%$ to a high of $76.72 \%$, whereas in rural areas it ranged from $63.07 \%$ to $93.96 \%$.

\section{DISCUSSION}

As per the operational guidelines on elimination of lymphatic filariasis, Government of India, coverage rate of $85 \%$ and above, which is sustained for a period of five years, is required for elimination of lymphatic filariasis in india. ${ }^{5}$ As far as Goa was concerned the overall coverage rate was either close to or higher that $85 \%$ for all the 
years under study. Coverage in urban areas was far lower than $85 \%$ for most of the years whereas coverage in rural areas was always in excess of $90 \%$.

Table 1: Compliance and coverage of mass drug administration (MDA) for elimination of lymphatic filariasis in Goa, India (2006-2010).

\begin{tabular}{|c|c|c|c|c|}
\hline & 2006 & 2007 & 2008 & 2010 \\
\hline $\begin{array}{l}\text { Study } \\
\text { population }\end{array}$ & $\begin{array}{l}\text { No. } \\
(\%)\end{array}$ & $\begin{array}{l}\text { No. } \\
(\%)\end{array}$ & $\begin{array}{l}\text { No. } \\
(\%)\end{array}$ & $\begin{array}{l}\text { No. } \\
(\%)\end{array}$ \\
\hline Urban & $\begin{array}{l}257 \\
(22.23)\end{array}$ & $\begin{array}{l}354 \\
(25.19)\end{array}$ & $\begin{array}{l}234 \\
(20.68)\end{array}$ & $\begin{array}{l}305 \\
(22.79)\end{array}$ \\
\hline Rural & $\begin{array}{l}896 \\
(77.77)\end{array}$ & $\begin{array}{l}1051 \\
(74.81)\end{array}$ & $\begin{array}{l}897 \\
(79.32)\end{array}$ & $\begin{array}{l}1033 \\
(77.21)\end{array}$ \\
\hline Total & $\begin{array}{l}1153 \\
(100)\end{array}$ & $\begin{array}{l}1405 \\
(100)\end{array}$ & $\begin{array}{l}1131 \\
(100)\end{array}$ & $\begin{array}{l}1338 \\
(100)\end{array}$ \\
\hline \multicolumn{5}{|c|}{ Eligible for MDA } \\
\hline Urban & $\begin{array}{l}253 \\
(98.44)\end{array}$ & $\begin{array}{l}348 \\
(98.30)\end{array}$ & $\begin{array}{l}230 \\
(98.29)\end{array}$ & $\begin{array}{l}295 \\
(96.72)\end{array}$ \\
\hline Rural & $\begin{array}{l}883 \\
(98.54)\end{array}$ & $\begin{array}{l}1002 \\
(95.33)\end{array}$ & $\begin{array}{l}862 \\
(96.09)\end{array}$ & $\begin{array}{l}1002 \\
(96.990\end{array}$ \\
\hline Total & $\begin{array}{l}1136 \\
(98.52)\end{array}$ & $\begin{array}{l}1350 \\
(96.08)\end{array}$ & $\begin{array}{l}1092 \\
(96.55)\end{array}$ & $\begin{array}{l}1297 \\
(96.93)\end{array}$ \\
\hline \multicolumn{5}{|c|}{ Coverage rate } \\
\hline Urban & $\begin{array}{l}140 \\
(55.33)\end{array}$ & $\begin{array}{l}312 \\
(89.65)\end{array}$ & $\begin{array}{l}177 \\
(76.95)\end{array}$ & $\begin{array}{l}128 \\
(43.38)\end{array}$ \\
\hline Rural & $\begin{array}{l}825 \\
(93.43)\end{array}$ & $\begin{array}{l}978 \\
(97.67)\end{array}$ & $\begin{array}{l}842 \\
(97.67)\end{array}$ & $\begin{array}{l}965 \\
(93.41)\end{array}$ \\
\hline Total & $\begin{array}{l}965 \\
(84.94)\end{array}$ & $\begin{array}{l}1290 \\
(95.55)\end{array}$ & $\begin{array}{l}1019 \\
(93.31)\end{array}$ & $\begin{array}{l}1093 \\
(85.71)\end{array}$ \\
\hline \multicolumn{5}{|c|}{ Compliance rate } \\
\hline Urban & $\begin{array}{l}119 \\
(85.00)\end{array}$ & $\begin{array}{l}267 \\
(85.57)\end{array}$ & $\begin{array}{l}129 \\
(72.00)\end{array}$ & $\begin{array}{l}75 \\
(58.59)\end{array}$ \\
\hline Rural & $\begin{array}{l}783 \\
(94.90)\end{array}$ & $\begin{array}{l}911 \\
(93.14)\end{array}$ & $\begin{array}{l}810 \\
(96.19)\end{array}$ & $\begin{array}{l}632 \\
(65.49)\end{array}$ \\
\hline Total & $\begin{array}{l}902 \\
(93.47)\end{array}$ & $\begin{array}{l}1178 \\
(91.31)\end{array}$ & $\begin{array}{l}939 \\
(92.14)\end{array}$ & $\begin{array}{l}707 \\
(64.68)\end{array}$ \\
\hline \multicolumn{5}{|c|}{ Coverage-Compliance gap } \\
\hline Urban & $\begin{array}{l}21 \\
(15.00)\end{array}$ & $\begin{array}{l}45 \\
(14.42)\end{array}$ & $\begin{array}{l}48 \\
(27.11)\end{array}$ & $\begin{array}{l}53 \\
(41.40)\end{array}$ \\
\hline Rural & $\begin{array}{l}42 \\
(5.09)\end{array}$ & $\begin{array}{l}67 \\
(6.85)\end{array}$ & $\begin{array}{l}32 \\
(3.80)\end{array}$ & $\begin{array}{l}333 \\
(34.50)\end{array}$ \\
\hline Total & $\begin{array}{l}63 \\
(6.52)\end{array}$ & $\begin{array}{l}112 \\
(8.68)\end{array}$ & $\begin{array}{l}80 \\
(7.85)\end{array}$ & $\begin{array}{l}386 \\
(35.31)\end{array}$ \\
\hline \multicolumn{5}{|c|}{ Effective coverage rate } \\
\hline Urban & $\begin{array}{l}119 \\
(47.03)\end{array}$ & $\begin{array}{l}267 \\
(76.7)\end{array}$ & $\begin{array}{l}129 \\
(56.08)\end{array}$ & $\begin{array}{l}75 \\
(25.42)\end{array}$ \\
\hline Rural & $\begin{array}{l}783 \\
(88.67)\end{array}$ & $\begin{array}{l}911 \\
(90.91)\end{array}$ & $\begin{array}{l}810 \\
(93.96)\end{array}$ & $\begin{array}{l}632 \\
(63.07)\end{array}$ \\
\hline Total & $\begin{array}{l}902 \\
(79.40)\end{array}$ & $\begin{array}{l}1178 \\
(87.25)\end{array}$ & $\begin{array}{l}939 \\
(85.98)\end{array}$ & $\begin{array}{l}707 \\
(54.51)\end{array}$ \\
\hline
\end{tabular}

Coverage was particularly low in urban areas in the year 2010 indicating that the MDA activity was not conducted effectively by the health personnel. This observed difference could be attributed to the different settings as far as urban and rural areas are concerned i.e. people in rural areas are more approachable and available at most times at their residences and local health workers have good rapport with them compared to urban areas wherein people may not be available at their homes due to their work schedule and moreover absence of primary health centre-sub health centre setting in urban areas usually leads to reluctance among urban people in accepting government programmes or strategies.

Kumar et al. ${ }^{6}$ in their study in Gujarat reported overall coverage rate of $85.2 \%$. Coverage in rural areas was reported to be $85.5 \%$ whereas in urban areas coverage was reported as $84.4 \%$. In a study in Pondicherry Nandha et al. ${ }^{7}$ reported coverage of MDA varying from $95.4 \%$ to $74.3 \%$ over the period of five years. A study conducted in Sri Lanka8 reported a drug coverage rate of $79.6 \%$

Compliance rate in Goa ranged from low of $64.68 \%$ to high of $93.47 \%$. compliance rate was particularly low in 2010 indicating that the repetitive nature and long duration of the strategy was leading to programme fatigue both among health workers and population at large thereby threatening the sustainability of the programme.

Kumar et al. ${ }^{6}$ reported overall compliance rate of $89.0 \%$ in Gujarat, rural compliance rate was $90.6 \%$ and urban area compliance rate was $87.8 \%$. Nandha et al. ${ }^{7}$ reported compliance rate ranging from $52.9 \%$ to $78.8 \%$ over the five year study period. Weerasooriya et al. ${ }^{8}$ reported drug compliance rate of $71.4 \%$ in Sri Lanka.

Coverage compliance gap was low in rural areas indicating that the MDA strategy was well accepted in the rural areas compared to urban areas. However the gap was high for both urban and rural areas for the year 2010 this could be probably due to below par monitoring and supervision of the programme in that year or could be attributed to programme fatigue due to long duration of the strategy. Kumar et $\mathrm{al}^{6}$ reported a coveragecompliance gap of $11.0 \%$ for Gujarat, the coveragecompliance gap of $12.2 \%$ in urban area was higher than in rural area $(9.4 \%)$.

Effective coverage correctly measures the success of the MDA strategy and if we use the criteria of at least $85 \%$ coverage than the strategy could be considered successful only for two years 2007 and 2008 wherein the overall effective coverage was above $85 \%$. If we consider urban and rural areas separately, in urban areas the strategy performed very poorly compared to rural areas. Kumar et al. ${ }^{6}$ reported effective coverage rate of $75.8 \%$ for Gujarat, this rate was $76.2 \%$ for rural area and $74.2 \%$.

\section{CONCLUSION}

Considering the criteria of $85 \%$ MDA coverage required to eliminate lymphatic filariasis in India, MDA rounds in Goa failed to reach the target of $85 \%$ coverage if effective coverage is considered as the parameter. Coverage, compliance, coverage-compliance gap and 
effective coverage rate were found to be consistently lower in urban areas compared to rural areas. For the state to reach elimination targets, the MDA strategy implementation would require thorough review and revamping. Action on this front would ensure that gains made in filarial elimination are sustained eventually leading to elimination of lymphatic filariasis in the state of Goa.

Funding: No funding sources Conflict of interest: None declared

Ethical approval: Not required

\section{REFERENCES}

1. Centre for Disease Control (CDC). Recommendations of the international task force for disease eradication. Morbidity and Mortality weekly Report. 1993;42:1-38.

2. Babu BV, Kar SK. Coverage, compliance and some operational issues of mass drug administration during the programme to eliminate lymphatic filariasis in Orissa, India. Tropical Med International Health. 2004;9(6):702-9.

3. Ottesen EA, Vijayasekaran V, Kumaraswami V, et al. A controlled trial of ivermectin and diethylcarbamazine in lymphatic filariasis. New England Journal of Medicine 1990, 322:1113-17.

4. Molyneux DH, Zagaria N. Lymphatic filariasis elimination: progress in global program development. Annals Tropical Med Parasitol. 2002; $96: 15$ s-40s.

5. Government of India. Operational guidelines on elimination of lymphatic filariasis. Directorate of National Vector Borne Disease Control Programme, Government of India, New Delhi, 2005.

6. Kumar P, Prajapati PB, Saxena D, Kavishkar AB, Kurian G. An evaluation of coverage and compliance of mass drug administration 2006 for elimination of lymphatic filariasis in endemic areas of Gujarat. Indian $\mathbf{J}$ Community Med 2008;33(1):38-42.

7. Nandha B, Sadanandane C, Jambulingam P, Das PK. Delivery strategy of mass annual single dose DEC administration to eliminate lymphatic filariasis in the urban areas of Pondicherry. Filaria J. 2007;6: 7.

8. Weerasooriya MV, Yahathugoda CT, Wickramasinghe D, Gunawardena KN, Dharmadasa RA, Vidanapathirana KK, et al. Social mobilization, drug coverage and compliance and adverse reactions in a mass drug administration (MDA) programme for the elimination of lymphatic filariasis in Sri Lanka. Filaria J. 2007;6:11.

Cite this article as: Perni SG, Motghare DD, Ferreira AM, Perni SS, Vaz FS, Kulkarni MS, Govekar S. Evaluation of mass drug administration for elimination of lymphatic filariasis in Goa, India. Int J Community Med Public Health 2015;2(3):259-62. 